\title{
Nannochloropsis gaditana grown outdoors in annular photobioreactors: Operation strategies
}

\author{
Natacha Nogueira ${ }^{\mathrm{a}, \mathrm{b}, *}$, Francisco J.A. Nascimento ${ }^{\mathrm{c}}$, César Cunha ${ }^{\mathrm{d}}$, Nereida Cordeiro ${ }^{\mathrm{b}, \mathrm{d}}$ \\ ${ }^{a}$ Mariculture Center of Calheta, Fisheries Directorate, 9370-133 Calheta, Portugal \\ ${ }^{\mathrm{b}}$ CIIMAR - Interdisciplinary Centre of Marine and Environmental Research, University of Porto, 4450-208 Matosinhos, Portugal \\ ${ }^{\mathrm{c}}$ Department of Ecology, Environment and Plant Sciences, Stockholm University, Stockholm, Sweden \\ ${ }^{\mathrm{d}}$ LB3-Faculty of Science and Engineering, University of Madeira, 9000-390 Funchal, Portugal
}

\section{A R T I C L E I N F O}

\section{Keywords:}

Nannochloropsis gaditana

Outdoor production

Harvest and dilution time

Lipid content

Fatty acid profile

\begin{abstract}
A B S T R A C T
Microalgae are a topic of intense research due to their potential applications in bio-based economy. However, sustainable commercial production is still overpriced due to high cultivation costs, harvesting and dewatering processes. In the present study, trials were conducted with the aim to improve daily operation strategies related to microalgae harvesting processes that did not compromise biomass productivity or the biochemical composition of the cultivated microalgae. Two experimental trials were performed in outdoor tubular annular photobioreactors to evaluate the effects of harvesting and medium dilution time (sunrise vs sunset) on Nannochloropsis gaditana biomass productivity, lipid and fatty acid content. Results showed that harvesting time had no significant effect on cell concentration and biomass productivity. Harvesting and medium dilution time did not affect lipid content. However, lipid content in samples collected at sunset was significantly higher than in samples collected at sunrise for both experimental treatments. The fatty acids profiles were mainly composed by polyunsaturated fatty acids, followed by mono-unsaturated fatty acids and saturated fatty acids. Regardless of medium dilution time, harvesting at sunset indicated that lipidic production (higher polyunsaturated fatty acids and lower saturated fatty acids) was favored without affecting the biomass productivity. The current study showed harvesting in the afternoon is a viable option for large production units that use semi-continuous strategy, without compromising biomass cell and lipid productivity.
\end{abstract}

\section{Introduction}

Microalgae are photosynthetic organisms that have during the past three decades been used as a food source for aquaculture [1] and for human food production [2]. More recently, their ability to produce value-added products, such as antioxidants and pigments, triacyclglycerols (TAG) and polyunsaturated fatty acids (PUFA) [3,4] attracted significant interest from researchers. Consequently, microalgae biomass production is perceived as an attractive industrial investment option [5], recognized and pursued by the food, feed, cosmetic and nutraceutical markets [6]. However, the feasibility of outdoor industrial production of algal biomass requires extensive pilot-scale research to determine the optimal strategy to optimize cultivation technology and the selection of an ideal lipid profile for the cultured strain. Such advancements are critical for the economical sustainability of outdoor production of algal biomass and its transition to large scale applications. Previous studies have reported improved practices that can increase biomass and lipid productivity in outdoor culturing facilities [5,7-9], but have also highlighted the challenges in accounting for how varying weather conditions can greatly affect microalgae growth rates [10] and biochemical composition [11-14]. These works indicate that efficient outdoor large-scale cultivation in closed systems is necessarily a balance between production costs, maximum biomass productivity and lipid productivity [15].

Most studies on optimization of microalgae cultivation are based on trial-and-error and/or design heuristics $[16,17]$, focusing on laboratory algae growth systems without accounting for outdoor weather variations [18]. Conventional approaches to improve biomass and lipid productivity of microalgae involve manipulation of nutritional and environmental factors [19]. Few studies address the combined aspects of operating outdoor closed photobioreactors (PBRs) in large scale units and its effects on growth and productivity parameters on microalgal production $[5,7,15]$. Algae grown in outdoor PBRs are inevitably exposed to variable incident light and water temperature, due to diurnal

\footnotetext{
* Corresponding author at: Mariculture Center of Calheta, Vila da Calheta, 9370-155 Calheta, Madeira, Portugal.

E-mail address: natacha.nogueira@madeira.gov.pt (N. Nogueira).
} 
and seasonal differences in irradiation with the potential to result in a circadian adaptation [20]. Examples of processes under control of the circadian clock are chemotaxis, phototaxis, photosynthesis and cell division [21], all likely to have important consequences for the productivity of outdoor PBRs. Several studies reported over 30\%-night losses of the biomass fixed during the day in outdoor cultivation regardless of the production technology adopted (open or closed PBRs) [22-24]. Such losses can significantly impact the biomass production capacity of solar-based algae cultures and therefore the suitability of strains for lipid production.

Harvesting of microalgae biomass in the afternoon has been proposed as a measure to mitigate respiration losses and increasing the productivity of in outdoor cultivation systems [25]. Richmond et al. [26] has also reported an increase in net productivity of $15-20 \%$ when harvesting was carried out mainly in the late afternoon, rather than in the morning. From a logistical perspective, harvesting microalgae from large industrial units at sunset would present the operational advantage of reducing the number of early morning procedures (e.g. harvest and medium dilution) and consequently allowing longer sunlight exposure to the diluted (renewed) cultures. This approach could have direct positive implications on the productivity parameters of microalgae, especially in winter season, when shorter exposure to light periods needs to be maximized to maintain sustainable microalgae growth rates. Additionally, this harvesting strategy could be economically advantageous, since the high cost of harvesting operations is mostly associated with power consumption of water pumps [27]. A shift to a higher power consumption during the night, when its electricity costs are lower in many regions, would result in lower auxiliary production costs.

The aim of this study was to investigate practices that could contribute to better operational strategies in large scale cultivation units without compromising biomass productivity and biochemical composition of the cultivated microalgae. In the experimental trials we evaluated the effect of two harvesting and medium dilution times on the lipid content, fatty acid profile and biomass productivity of outdoor Nannochloropsis gaditana cultures. This robust microalga can cope with varying environmental conditions, such as salinity, nutrient deficiency and light intensity, being cultivated in various types of facilities, both indoor and outdoor [5,8,28-32].

\section{Materials and methods}

\subsection{Facilities}

The experiments were performed at Buggypower, a microalgae commercial production unit located in Porto Santo Island (Madeira Archipelago, Portugal) that uses $400 \mathrm{~L}$ vertical tubular photobioreactors (PBRs) for the production of biomass of several species, including Nannochloropsis gaditana.

Regular operation of the industrial unit applies semi-continuous regime, collecting a variable percentage $(5-40 \%)$ of the culture every morning, followed by the addition of new medium. Due to the large culture volumes harvested daily, temporary storage of the biomass is normally done prior to centrifugation using a $110 \mathrm{~m}^{3}$ tank supplied with paddles to mix the microalgae cultures of the different PBRs.

\subsection{Microalgal strains and culture medium}

The marine species $N$. gaditana (Lubián CCMP 527) was grown in laboratory conditions in $1 \mathrm{~L}$ flasks filled with autoclaved $36 \mathrm{ppm}$ seawater and Algal medium $\left(\mathrm{NaNO}_{3}, 2 \mathrm{mM} ; \mathrm{NaH}_{2} \mathrm{PO}_{4}, 0.1 \mathrm{mM} ; \mathrm{ZnCl}_{2}\right.$, $1 \mu \mathrm{M} ; \mathrm{MnCl}_{2}, 1 \mu \mathrm{M} ; \mathrm{Na}_{2} \mathrm{MoO}_{4}, 1 \mu \mathrm{M} ; \mathrm{CoCl}_{3}, 0.1 \mu \mathrm{M} ; \mathrm{CuSO}_{4}, 0.1 \mu \mathrm{M}$; $\mathrm{C}_{6} \mathrm{H}_{5} \mathrm{FeO}_{7}, 20 \mu \mathrm{M}$; EDTA, $26.4 \mu \mathrm{mol} \mathrm{l}^{-1}$ adapted from Fabregas et al. [33]). Temperature was kept at $21{ }^{\circ} \mathrm{C}$, and light was provided in a 12 light: 12 dark cycle at $150 \mu \mathrm{Em}^{-2} \mathrm{~s}^{-1}$ measured on the outer surface of the culture flasks (LI-250A light meter). Cultures were continuously bubbled with compressed HEPA-filtered air, supplied at a rate of $1.5 \mathrm{~L} \mathrm{~min}^{-1}$. To ensure even distribution of nutrients and light exposure, besides air supply, flask cultures were manually stirred three times a day. Laboratory cultures were allowed to grow until nutrient exhaustion and then transferred outdoor into four recirculating $40 \mathrm{~L}$ flat panels. The flat panels cultures were allowed to grow autotrophically during a week to achieve the cell concentration needed for the trials $\left(2 \times 10^{8}\right.$ cells $\left.\mathrm{mL}^{-1}\right)$. To avoid contamination, these seed cultures were maintained in UV-treated natural seawater ( $36 \mathrm{ppm}$ ), chemically sterilized with sodium hypochlorite, and further deactivated by strong aeration and filtration over active carbon. Algal medium was added to the seawater to adjust nitrate to a starting concentration of $250 \mathrm{ppm}$ in the seed cultures. Daily samples of $25 \mathrm{~mL}$ were manually collected to determine cell number, nitrate concentration and biomass dry weight from the seed cultures (see Section 2.5 Analytical procedures).

\subsection{Photobioreactors (PBRs) and operation mode}

Six annular PBRs were used to perform the trials in Buggypower facilities, Porto Santo (Portugal). Each PBR had a working volume of $100 \mathrm{~L}$, consisting of two acrylic cylinders of distinct diameters (400 and $300 \mathrm{~mm}$ ) with the inner cylinder placed inside the outer one and closed at the bottom and at the top tube (Fig. 1). The arrangement of the PBR's was optimized for solar radiation capture, being oriented east-west with the distance between the outer tubes set to $0.30 \mathrm{~m}$ to minimize shading. Each tube was provided with bottom aeration and $2 \% \mathrm{CO}_{2}$ mixed with air.

The $\mathrm{pH}$ of the culture medium was kept at 7.5 by on-demand injection of pure $\mathrm{CO}_{2}$ into the inlet of the air stream, located at the bottom of the chamber. The air flow rate entering from the bottom of each photobioreactor was $0.1(\mathrm{v} / \mathrm{v} / \mathrm{m})$ in all PBR's. Air outlet was located at the top opening of each annular chamber. The remaining area of the chamber's top was capped to limit entry of air-borne contaminants. The solar radiation received by the facility was measured with a thermoelectric pyranometer (LI-200) connected to a PC control unit.

\subsection{Experimental procedure}

The trials were performed outdoors during winter season and divided into two experimental sets: 1- Harvest time; and 2- Harvest and medium dilution time. First, the tubular PBR's were inoculated with seed cultures of $N$. gaditana from the $40 \mathrm{~L}$ flat panel reactors at the end

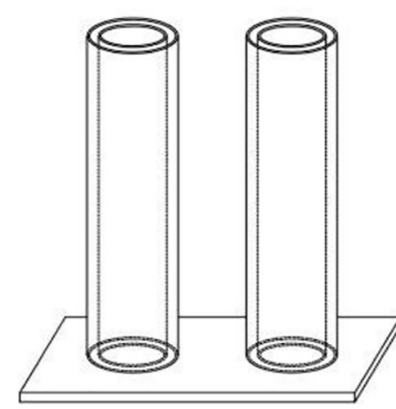

Perspective
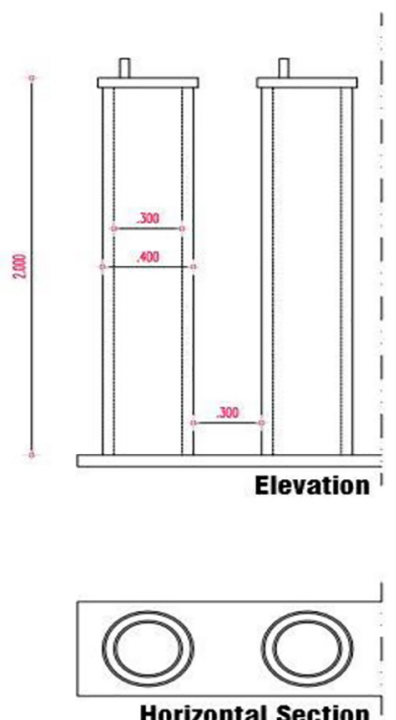

Horizontal Section
Fig. 1. Schematic representation of the experimental $100 \mathrm{~L}$ photobioreactors set outdoor. 
of exponential phase grown. These cultures were used as an inoculum at a ratio of $1: 5(\mathrm{v} / \mathrm{v})$ to achieve starting cell concentrations of $4 \times 10^{7}$ cell $\mathrm{mL}^{-1}$

Once cultures approached late exponential phase $\left(1.35 \times 10^{8} \pm 0.15\right.$ cell $\left.\mathrm{mL}^{-1}\right)$, harvesting and daily dilutions at a renewal rate of $15 \%$ of the volume of cultures were carried until the end of both trials. To ensure that cultures were nutrient sufficient during the trials, sub-samples of the harvested biomass were used for nitrate and phosphate determination (see Section 2.5 Analytical procedures) prior to medium dilution. Preliminary tests showed that a nitrate concentration of $150 \mathrm{ppm}$ in the tubular PBRs used in our experiment do not deplete in less than $24 \mathrm{~h}$. The seawater used to dilute the cultures was then prepared by supplementing UV-treated seawater with Algal medium adjusted to keep the cultures with $150 \mathrm{ppm}$ nitrates. Samples of $100 \mathrm{~mL}$ of the harvested biomass were also used to assess the algae biomass dry weight $\left(\mathrm{g} \mathrm{L}^{-1}\right)$, cell concentration $\left(10^{6}\right.$ cell $\left.\mathrm{mL}^{-1}\right)$ of the previous day (see Section 2.5 Analytical procedures) and to monitor cultures $\mathrm{pH}$ and temperature $\left({ }^{\circ} \mathrm{C}\right)$. Daily ambient temperatures ranged from 17 to $21{ }^{\circ} \mathrm{C}$ and irradiance between 2 and $20 \mathrm{MJ} \mathrm{m}^{-2}$ day $^{-1}$.

\subsubsection{First experimental set- effects of harvest time}

The first experimental set ran for twelve days and aimed at evaluating the effect of harvesting $N$. gaditana cultures at sunset without simultaneous medium dilution. In three of the six replicate PBR's, harvesting was performed daily after sunset ( 6 p.m.), and medium dilution occurred in the following morning (sunrise), approximately $12 \mathrm{~h}$ after harvesting (named HSSDSR). In another set of three PBR's (control set), harvesting and medium dilution was performed daily in the morning at 7 a.m. (named $\mathrm{HDSR}_{1}$ ). At day one and day twelve of harvesting, additional samples were collected at sunrise and sunset from each biological replicate to determine lipid and fatty acid content (see Section 2.5 Analytical procedures)

\subsubsection{Second experimental set- effects of harvest and medium dilution time}

On the second experimental set, the effect of harvesting time with simultaneous medium dilution was evaluated for nine days. PBR's were inoculated as in the first experimental set with $N$. gaditana cultures from the flat panels. Three PBR's with N. gaditana were harvested at sunset (6 p.m.) followed by medium dilution (named HDSS). On the other three PBR's harvesting and medium dilution occurred at sunrise (named $\mathrm{HDSR}_{2}$ ) as done in trial 1 for the HDSR (control set). Similarly, to the harvest time experimental set, samples for chemical analysis were collected at the beginning and at the end of the experiment.

\subsection{Analytical procedures}

Cell concentration, biomass dry weight, lipid and fatty acid content were used as parameters of the culture state in both experimental sets. Daily samples of $100 \mathrm{~mL}$ were collected to determine nutrient concentration (2.5.1) and microalgae productivity parameters (2.5.2). For biochemical analysis $(2.5 .3,2.5 .4), 1 \mathrm{~L}$ of each PBR culture was centrifuged, the supernatant was discarded and tubes containing microalgal biomass were stored at $-20{ }^{\circ} \mathrm{C}$.

\subsubsection{Nutrient determination}

Prior to analysis, $10 \mathrm{~mL}$ aliquots of the culture samples were filtered through glass fiber filters. The concentration of nitrate and phosphate in the culture media were determined by spectrophotometric determination, according to Clesceri et al. [34].

\subsubsection{Microalgae productivity}

The cell concentration was determined by cell counting under an optical microscope (Axio Scope A.1) using a Neubauer chamber $(20 \times$ ) and the biomass dry weight determination was performed according to Zhu \& Lee [35]. Briefly, $75 \mathrm{~mL}$ of samples were taken from each replicate, filtered and washed with $100 \mathrm{~mL}$ of a $0.5 \mathrm{M} \mathrm{NH}_{4} \mathrm{HCO}_{2}$ solution through a pre-dried and pre-weighted Whatman GF/C filters of $0.7 \mu \mathrm{m}$ pore size (Millipore Ireland Ltd.). Then, the samples were dried for $24 \mathrm{~h}$ at $95{ }^{\circ} \mathrm{C}$, cooled down in a vacuum desiccator for $2 \mathrm{~h}$ and weighted again.

The daily biomass productivity (BP; $\mathrm{g} \mathrm{L}^{-1}$ day $^{-1}$ ) during the culture harvesting periods was calculated from the equation:

$\mathrm{BP}=\left[\left(\mathrm{V}_{\mathrm{PBR}} *(\%\right.\right.$ harvest $\left./ 100) * \mathrm{dw}\right] /$ day $/ \mathrm{V}_{\mathrm{PBR}}$

where, $\mathrm{V}_{\mathrm{PBR}}$ is the $\mathrm{PBR}$ volume (L); \% harvest is the daily harvest (15\%) and $\mathrm{dw}$ is the biomass dry weight $\left(\mathrm{g} \mathrm{L}^{-1}\right)$.

The cellular lipid productivity (LP; $\mathrm{mg} \mathrm{L}^{-1}$ day $^{-1}$ ) was calculated as the product of BP and the lipid content in the dry biomass (w/w), according to Dickinson et al. [36]:

$\mathrm{LP}=\mathrm{BP} *$ lipid $/$ biomasss $(\mathrm{w} / \mathrm{w})$

Prior to the beginning of semi-continuous regimen and at the end of the experiments, harvested biomass was washed with distilled water, centrifuged at $4000 \mathrm{rpm}$ for $10 \mathrm{~min}$ (HLMac CT Series, rotor T6AP; 4170 maximum RCF) and freeze-dried (Labconco Freezone freeze dry $4.5 \mathrm{~L}$ ) until further chemical analysis.

\subsubsection{Lipid extraction}

The lipid extraction was performed according to modified Bligh and Dyer [37]. Briefly, to dried algal biomass was added $3 \mathrm{~mL}$ of a methanol: chloroform mixture $(2: 1, \mathrm{v} / \mathrm{v})$ followed by $400 \mu \mathrm{L}$ of a saturated solution of $\mathrm{KCl}$ and $2 \mathrm{~mL}$ of chloroform. After homogenization, $2 \mathrm{~mL}$ of distilled water were added, and the mixture was left stirring for $15 \mathrm{~min}$. Then, the sample was let to set, and the organic phase was removed and dried in $\mathrm{Na}_{2} \mathrm{SO}_{4}$ filters. At the end, solvent was evaporated in a Büchi rotavapor R-200, in order to proceed to lipids quantification. Lipid content was quantified gravimetrically. Lipids contents are presented relatively to dry biomass weight (\% dw) as average of at least two replicates.

\subsubsection{Fatty acid analysis}

Lipid extracts were analysed for their fatty acid composition as fatty acid methyl esters (FAMEs) as described in Nogueira et al. [38]. Briefly, the fatty acids were converted to FAMEs by adding a mixture of ethyl acetate-methanol $(1: 19 ; \mathrm{v} / \mathrm{v})$ to lipid extract aliquots that were after placed at $80{ }^{\circ} \mathrm{C}$ for $1 \mathrm{~h}$. FAMEs were analysed by gas chromatography (Agilent HP 6890) equipped with a mass selective detector (Agilent 5973) and a fused silica capillary column Supelcowax ${ }^{\mathrm{TM}} 10$ (30 m $\times 0.25 \mathrm{~mm}$ inner diameter, $0.25 \mu \mathrm{m}$ film thickness) from Supelco. The chromatographic conditions were: initial temperature, $40{ }^{\circ} \mathrm{C}$ for $5 \mathrm{~min}$; temperature gradient, $2{ }^{\circ} \mathrm{C} \mathrm{min}-1$; final temperature, $250{ }^{\circ} \mathrm{C}$ for $5 \mathrm{~min}$; injector temperature, $260{ }^{\circ} \mathrm{C}$; transfer-line temperature, $260{ }^{\circ} \mathrm{C}$; split ratio, $1: 100$. Helium was used as the carrier gas with a flow of $1.0 \mathrm{~mL} \mathrm{~min}^{-1}$.

The FAMEs were identified through comparison of retention times and mass spectra obtained by spectra library Wiley-NIST and/or using two standard samples: Bacterial acid methyl esters CP mix; and Supelco 37 component FAME's mix, from Supelco. To quantify the fatty acids of the sample it was used heneicosanoic acid (C21:0) as an internal standard. The results were expressed in percentage of total fatty acids, being the quantification made according to the response factor determined for each fatty acid present in the standards, in comparison with internal standard.

\subsection{Statistical analyses}

Repeated measure One-way ANOVA was used to test for significant differences between treatments at 5\% confidence level on the dependent variables measured daily for 12 days, namely: cell density, biomass dry weight and productivity. One-way Anova was conducted to detect significant differences in chemical parameters that were only measured at the end of the 12 days trials, namely lipids and FAME's. 
Table 1

$N$. gaditana grown outdoors in annular tubular PBR's, in semi-continuous system (15\% dilution): cell concentration, dry weight and biomass productivity.

\begin{tabular}{llll}
\hline & $\begin{array}{l}\text { Cell concentration }\left(\times 10^{6}\right. \\
\left.\text { cell } \mathrm{mL}^{-1}\right)\end{array}$ & $\begin{array}{l}\text { Dry weight } \\
\left(\mathrm{g} \mathrm{L}^{-1}\right)\end{array}$ & $\begin{array}{l}\text { Productivity } \\
\left(\mathrm{g} \mathrm{L}^{-1} \text { day }^{-1}\right)\end{array}$ \\
\hline $\mathrm{HDSR}_{1}$ & $126.36 \pm 31.15$ & $0.52 \pm 0.08$ & $78.04 \pm 14.20$ \\
$\mathrm{HSSDSR}$ & $144.94 \pm 30.04$ & $0.55 \pm 0.06$ & $81.70 \pm 9.80$ \\
$\mathrm{HDSR}_{2}$ & $121.17 \pm 35.28$ & $0.69 \pm 0.06$ & $105.33 \pm 8.40$ \\
$\mathrm{HDSS}$ & $111.63 \pm 32.41$ & $0.64 \pm 0.08$ & $94.26 \pm 9.72$ \\
\hline
\end{tabular}

Data are given as means $\pm \mathrm{SD}(n=3) . \mathrm{HDSR}_{1}$ and $\mathrm{HDSR}_{2}=$ harvesting and dilution at sunrise; HSSDSR = harvesting at sunset followed by dilution later at sunrise; HDSS = harvesting and medium dilution at sunset.

Data in figures and tables are reported as mean \pm SD. All variables were checked for normality, homogeneity of variance, using the Kolmogorov-Smirnoff and the Levene tests, respectively. Sphericity of repeated measure ANOVA was checked with Mauchly's test. Statistical analyses were performed using SPSS. v 23 for Windows.

\section{Results and discussion}

\subsection{Effects on biomass, cell density and productivity}

The present study was focused on evaluating the effect of harvesting microalgae biomass late in the afternoon in order to expedite morning processes in outdoor microalgae industrial facilities. Experiments were conducted outdoors during winter season and the effects of harvesting and medium dilution at sunset were evaluated on $N$. gaditana cell and lipid productivity.

The first experimental set aimed at evaluating the effect of harvesting the microalgae at sunset, as this procedure can reduce the morning procedures in large industrial plants using semi-continuous regimes. Interestingly, harvesting at sunset did not result in a significant reduction in biomass, cell density or productivity (Table 1). Still, medium dilution time in the HSSDSR treatment was performed almost $12 \mathrm{~h}$ after harvesting, which may contribute to the building of foam at the top of the reactor. This phenomenon is commonly observed in microalgal cultures [39] due to the presence of specific molecules excreted by the microalgae and is amplified in confined geometries where small bubbles are generated [40]. The accumulation of foam should be minimized to avoid biomass losses by entrainment and the development of bacteria. On the second experimental set, the advantages of further minimizing procedure times in the morning and avoiding possible foam formation at the top of PBR's were evaluated, as harvesting and medium dilution were both performed at sunset. Similar to the first experimental trial, our results indicate that the employment of a complete semi-continuous system at sunset did not significantly affect cell density, dry weight or biomass productivity $\left(\mathrm{g} \mathrm{L}^{-1}\right.$ day $\left.^{-1}\right)(p>0.05)$ (Table 1).

Biomass productivity from the first experimental set was on average $78 \mathrm{mg} \mathrm{L}^{-1}$ day $^{-1}$ for the morning harvesting treatment (HDSR) and $82 \mathrm{mg} \mathrm{L}^{-1}$ day $^{-1}$ for cultures harvested at sunset (HSSDSR), which is comparable to other outdoor $N$. gaditana cultures in different PBR's designs ("green wall panels" [41]; plastic tubular PBR's [42]); raceway ponds [8]. Nonetheless, biomass productivity values were low compared to other works $[5,28,43,44]$, representing only $16-30 \%$ of the maximum productivity found in the above-mentioned studies. This may be a result of several factors that influence productivity and are related with the design of the PBR's; the bottleneck effect [45]; inefficient mixing [46]; temperature; and or irradiation levels [15]. In fact, differences in the irradiation levels could also contribute to explain the higher biomass productivity found in the second experimental set. Though both experimental sets were conducted consecutively in the same time of the year, the mean irradiance in the second experimental set was more than the double of the first experimental set (13.4 $\mathrm{MJ} \mathrm{m}^{2}$ day $^{-} 1$ and $5.6 \mathrm{MJ} \mathrm{m}^{2}$ day $^{-1}$, respectively).

\subsection{Effects on lipid and fatty acid content}

Lipid content (TL) of the two experimental sets (Fig. 2) were comparable to those obtained by other studies working with Nannochloropsis oculata grown outdoors, during winter season such as by Olofsson et al. [15]. At the end of the first experimental set, TL of microalgae $(\% \mathrm{dw})$ was similar for both harvesting times when lipid samples were collected in the morning $\left(9.69 \pm 0.46 \%\right.$ for $\mathrm{HDSR}_{1}$ and $10.10 \pm 0.41 \%$ for HSSDSR). When samples of the same experimental set were collected at sunset, there was a slight, but significant increase $(p<0.05)$ in lipids of both harvesting times $(11.49 \pm 0.89 \%$ for HDSR $_{1}$ and $12.11 \pm 1.19 \%$ for HSSDSR). Differences in lipid content of the same cultures collected at different times of the day suggest that harvesting at sunset would be favorable for lipid purposes, without

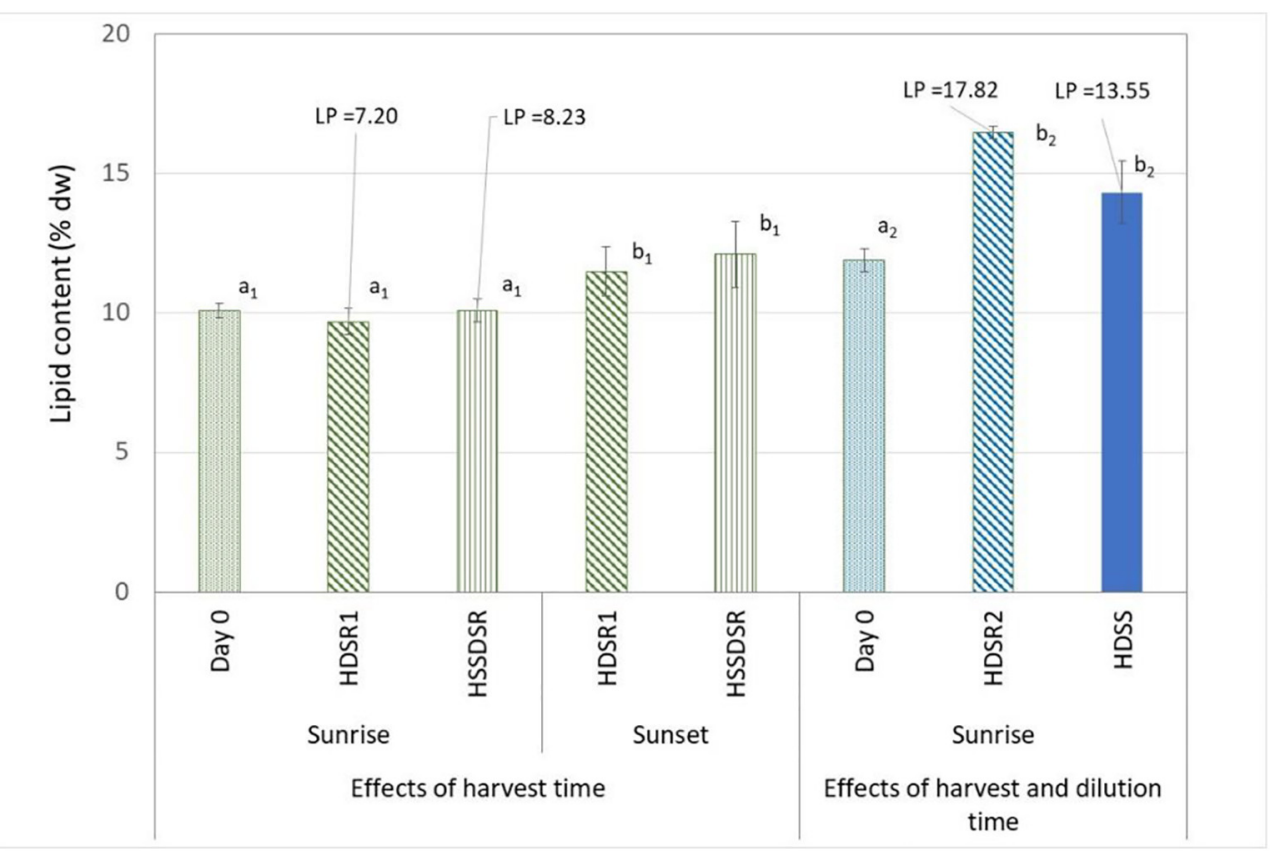

Fig. 2. Lipid content ( $\% \mathrm{dw}$ ) prior to the beginning of the semi-continuous systems and at the end of the two experimental sets. In the harvest time experimental set, samples for lipid determination were collected at sunrise and at sunset in both treatments. In the harvest and medium dilution experimental set, lipid samples were collected at sunrise. Error bars represent standard deviation ( $n=2)$. Different subscripts indicate significant differences $(p<0.05)$ in lipid content within each experimental set (1 or 2). HDSR 1 and $\mathrm{HDSR}_{2}$ : harvesting and dilution at sunrise; HSSDSR: harvesting at sunset followed by dilution later at sunrise; HDSS: harvesting and medium dilution at sunset. LP: Lipid productivity $\left(\mathrm{mg} \mathrm{L}^{-1}\right.$ day $\left.^{-1}\right)$. 
affecting cell productivity in terms of number or biomass dry weight. Increased lipid and fatty acid content of samples collected at sunset has also been observed by other authors $[47,48]$ and can be related to the variability in lipid content and fatty acids composition of microalgae during its growth cycle $[49,50]$ in which daily light and temperature play a central role [8]. In accordance to the results of the present study, Tambouric et al. [51] demonstrated that $N$. oculata grown outdoors were more active beyond midday under elevated afternoon and earlyevening temperatures. Further, the same authors suggested that high temperatures at the end of the light period (sunset) lead to a positive hysteresis in the oxygen evolution rate, resulting in higher relative photosynthetic activity towards the end of the day.

In the second experimental set, lipid content was also not affected by the harvesting and medium dilution time as both treatments presented similar lipid content $\left(16.48 \pm 0.23 \%\right.$ for $\mathrm{HDSR}_{2}$ and $14.32 \pm 1.12 \%$ for HDSS), but in accordance with biomass productivity results, higher lipid content and productivity were observed when compared with the first experimental set. Overall, lower cell density with higher dry weight resulted in higher lipid productivity, with the highest lipid content and lipid productivity being observed in the harvesting and medium dilution at sunrise treatment $\left(\mathrm{HDSR}_{2}\right)$. Irradiance is a very useful tool to modify the biochemical composition of the marine microalga $N$. gaditana under semi-continuous culture $[52,53]$. As stated previously, cultures of the second experimental set experienced higher light availabilities than the first experimental set (13.4 $\mathrm{MJ} \mathrm{m^{2 }}$ day $^{-} 1$ and $5.6 \mathrm{MJ} \mathrm{m}^{2}$ day $^{-1}$, respectively). Further, although the two experiments were performed consecutively it is normal that besides light intensity, short term changes in day length and photoperiod occur, which in accordance to Olofsson et al. [15] may contribute to explain the higher TL levels found in the second experiment.

The fatty acids composition of marine $N$. gaditana after applying the proposed experimental conditions, depicted in Table 2, confirm the potential use of $N$. gaditana as a natural resource of high commercial value PUFAs [54,55].

The fatty acid profiles of microalgae are an important indicator of downstream process requirements, particularly with respect to unsaturated fatty acid content [7]. In all our experimental conditions, fatty acids profiles were highest in polyunsaturated fatty acids (PUFAs), followed by monounsaturated fatty acids (MUFAs) and lowest in saturated fatty acids (SFAs). Though the proportion of PUFAs of each strain may be the most diverse [15], it is assumed that PUFAs increase in winter season, due to lower light intensity $[15,56]$ and lower temperatures [54]. Similar PUFAs contents were found by Olofsson et al. [15] in N. oculata grown outdoors in winter season at analogous temperature and radiations levels. Moreover, results found in the present study could also be explained by the fact that fatty acids samples were collected in the morning. SFAs and MUFAs, along with carbohydrates, act as storage material $[48,57]$ decreasing during the night, whereas the relative proportion of PUFA, namely EPA (C20:5 - eicosapentanoic acid), mainly associated with galactolypids, increases in the dark period. In future experiments, it would be interesting to collect samples for fatty acids determination both in the morning and in the afternoon to further investigate if the fatty acids composition decreases significantly during the night following Chini Zitelli et al. [57].

Still, our findings highlight the tendency of $N$. gaditana cultures to produce higher PUFAs and lower SFAs, when harvesting of biomass occurred at sunset, regardless of the medium dilution time. Thus, if PUFAs are intended, the proposed harvesting timetable of the current study would be beneficial.

Furthermore, the fatty acid profiles showed that predominance was consistent in all the experimental conditions, with palmitic acid (C16:0) accounting for 12.9 to $20.5 \%$ of the SFAs; palmitoleic acid (C16:1) for $21-38 \%$ of the MUFAs and EPA for $45-85 \%$ of total PUFAs. Palmitic and palmitoleic acid are major fatty acids in semi-continuous [58], batch [59] and continuous cultures [60,61] and are assumed to be the major fatty acids of microalgae strains of Eustigmatophyte [62]. EPA, a functional fatty acid with great benefits to human health [63], accounted for 18 to $38 \%$ of the total fatty acids detected (Table 2). In comparison with previous studies $N$. gaditana grown in our experimental conditions presented higher amounts of EPA, regardless of the semi-continuous timetable [5,43]. However, when normalizing EPA to total lipid content (Fig. 3), similar values to those reported by Olofsson et al. [15] were found. Normalized EPA content ranged between 5.5\% in the $\mathrm{HDSR}_{2}$ treatment and $18 \%$ in the samples collected at sunset and medium renewed $12 \mathrm{~h}$ later (HSSDSR).

\subsection{Implications for feasibility of outdoor cultivation}

The majority of microalgal production occurring in outdoor cultivation still faces biotechnological and economical challenges [4]. In order for these algal production systems to increase their competitiveness and economic viability, different strategies and routines would need to be applied [4]. The operation strategy applied in the current work aimed at increasing the exposition time of the cultures to sunlight, particularly in winter season, with the potential advantage of reducing harvesting costs without compromising biological and biochemical parameters of the cultures. Our results indicate that harvesting and renewing the medium in late afternoon is feasible and present no significant disadvantages in term of biomass production and lipid content. In fact, lipid content of algae harvested in the afternoon was significantly higher in our trials, suggesting that this procedure could

Table 2

Fatty acid (\% relatively to the total of the fatty acids detected) of $N$. gaditana grown in outdoor tubular annular photobioreactors at the end of semi-continuous systems.

\begin{tabular}{|c|c|c|c|c|c|c|c|c|c|c|c|c|}
\hline & $\mathrm{HDSR}_{1}$ & & & HSSDSF & & & $\mathrm{HDSR}_{2}$ & & & HDSS & & \\
\hline C14:0 & 2.64 & \pm & $0.05^{\mathrm{a}}$ & 2.39 & \pm & $0.05^{\mathrm{b}}$ & 2.49 & \pm & $0.14^{\mathrm{a}}$ & 2.03 & \pm & $0.11^{\mathrm{a}}$ \\
\hline $\mathrm{C} 16: 0$ & 16.82 & \pm & $0.10^{\mathrm{a}}$ & 12.90 & \pm & $0.01^{\mathrm{b}}$ & 20.51 & \pm & $0.01^{\mathrm{a}}$ & 17.89 & \pm & $0.20^{\mathrm{b}}$ \\
\hline C18:0 & 0.23 & \pm & $0.01^{\mathrm{a}}$ & 0.41 & \pm & $0.01^{\mathrm{b}}$ & 0.78 & \pm & $0.01^{\mathrm{a}}$ & 0.53 & \pm & $0.01^{b}$ \\
\hline C16:1 & 37.99 & \pm & $0.16^{\mathrm{a}}$ & 30.39 & \pm & $0.01^{\mathrm{b}}$ & 27.12 & \pm & $0.60^{\mathrm{a}}$ & 20.51 & \pm & $0.02^{\mathrm{b}}$ \\
\hline C18:1 & 1.76 & \pm & $0.01^{\mathrm{a}}$ & 1.59 & \pm & $0.01^{\mathrm{b}}$ & 7.26 & \pm & $0.12^{\mathrm{a}}$ & 4.52 & \pm & $0.09^{b}$ \\
\hline $\mathrm{C} 18: 2$ & 0.94 & \pm & $0.08^{\mathrm{a}}$ & 1.43 & \pm & $0.02^{\mathrm{b}}$ & 2.39 & \pm & $0.10^{\mathrm{a}}$ & 2.94 & \pm & $0.06^{\mathrm{b}}$ \\
\hline C18:3 & 0.36 & \pm & $0.03^{\mathrm{a}}$ & 0.37 & \pm & $0.02^{\mathrm{a}}$ & 6.90 & \pm & $0.01^{\mathrm{a}}$ & 7.39 & \pm & $0.02^{\mathrm{b}}$ \\
\hline C20:4 & 4.77 & \pm & $0.14^{\mathrm{a}}$ & 7.41 & \pm & $0.01^{\mathrm{b}}$ & 2.25 & \pm & $0.06^{\mathrm{a}}$ & 3.33 & \pm & $0.05^{\mathrm{b}}$ \\
\hline $\mathrm{C} 20: 5$ & 33.89 & \pm & $0.08^{\mathrm{a}}$ & 41.56 & \pm & $0.08^{\mathrm{b}}$ & 18.76 & \pm & $0.08^{\mathrm{a}}$ & 30.48 & \pm & $0.10^{\mathrm{b}}$ \\
\hline Total - SFAs & 20.04 & \pm & $0.17^{\mathrm{a}}$ & 16.19 & \pm & $0.04^{\mathrm{b}}$ & 24.59 & \pm & $0.19^{\mathrm{a}}$ & 21.20 & \pm & $0.30^{\mathrm{b}}$ \\
\hline Total -MUFAs & 39.74 & \pm & $0.16^{\mathrm{a}}$ & 31.99 & \pm & $0.04^{\mathrm{b}}$ & 34.41 & \pm & $0.48^{\mathrm{a}}$ & 25.03 & \pm & $0.06^{\mathrm{b}}$ \\
\hline Total - PUFAs & 40.22 & \pm & $0.31^{\mathrm{a}}$ & 51.83 & \pm & $0.04^{\mathrm{b}}$ & 41.00 & \pm & $0.28^{\mathrm{a}}$ & 53.77 & \pm & $0.24^{\mathrm{b}}$ \\
\hline
\end{tabular}

HDSR $_{1}$ and HDSR 2 : harvesting and dilution at sunrise; HSSDSR: harvesting at sunset and dilution later at sunrise; HDSS: harvesting and dilution at sunset. SFAs: saturated fatty acids; MUFAs: monounsaturated fatty acids; PUFAs: polyunsaturated fatty acids. Data are given as means \pm SD $(n=3)$. Different superscripts in the same row indicate significant differences $(\mathrm{p}<0.05)$ for the same fatty acid within each experimental set. 


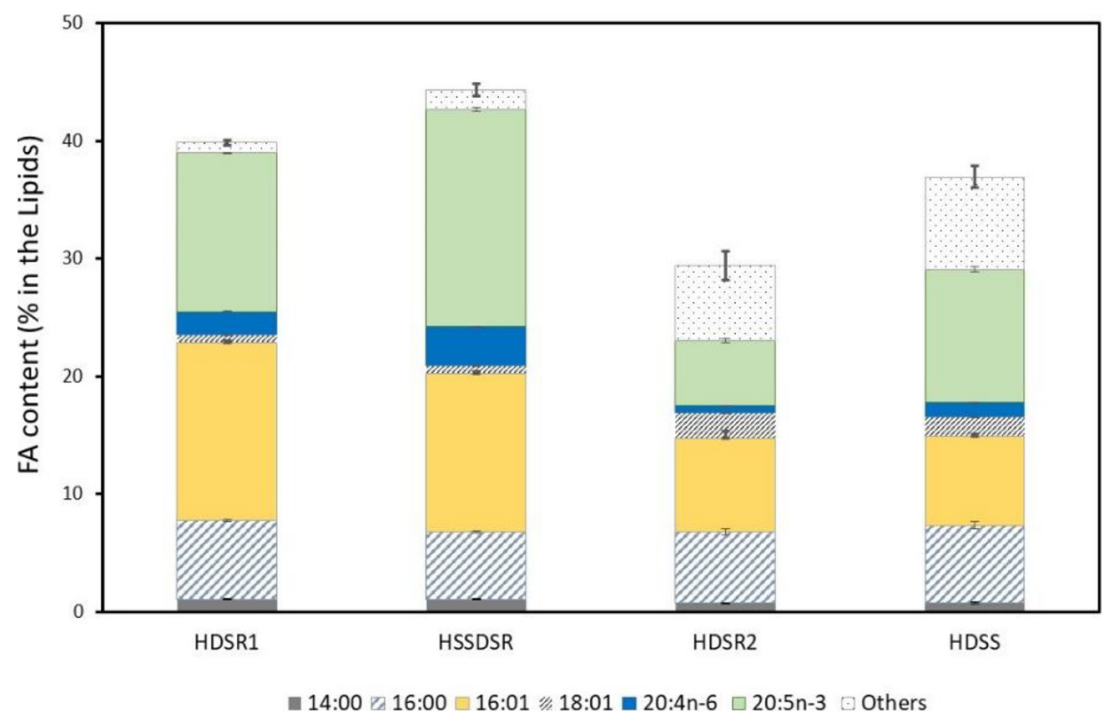

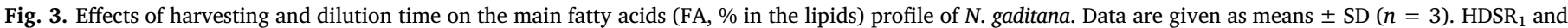
$\mathrm{HDSR}_{2}$ : harvesting and dilution at sunrise; HSSDSR: harvesting at sunset and dilution later at sunrise; HDSS: harvesting and dilution at sunset.

actually benefit microalgal lipid production.

Still, the value semi-continuous at sunset production represents an effective alternative to sunrise processes, should continue to be assessed in future studies. Particularly, the value of adjusting semi-continuous operational routines like harvesting frequency and percentage should be evaluated. Moreover, research on nutrient supply strategies, such as induced stress by N-deficiency [28]; two-stage cultivation [64] and nutrient resupply at sunset [65] should also be combined with sunset harvesting and medium dilution procedures, as these procedures are known to trigger the accumulation of lipids in this microalgae species without loss of productivity.

\section{Conclusions}

This work tested possible negative effects to biomass production and lipid content of an alternative operation strategy in semi-continuous systems that could be biologically and economically advantageous for industrial microalgae production plants. Biomass productivity of $N$. gaditana was not affected by harvesting and medium dilution at sunset. Actually, higher percentage of PUFAs and fatty acids content were found in cultures subjected to semi-continuous system at sunset. Thus, our results indicated that harvesting at sunset will benefit productivity parameters of lipid and PUFA production, especially in winter season, when a reduced number of natural light hours result in the need to maximize microalgae exposure to light. Economically, these findings may open opportunities to reduce production costs related with the use of harvest and water and centrifugation pumps in regions where special night energy rates are available.

\section{CRediT authorship contribution statement}

Natacha Nogueira: Conceptualization, Investigation, Formal analysis, Writing - original draft. Francisco J.A. Nascimento: Investigation, Writing - review \& editing. César Cunha: Writing review \& editing. Nereida Cordeiro: Writing - original draft, Writing - review \& editing, Supervision.

\section{Declaration of competing interest} ally.

The authors declare no conflict of interest financially and person-

\section{Acknowledgments}

The authors are grateful to Buggypower's for enabling the realization of this work and their technical staff for assistance during the sampling period. This research did not receive any specific grant from funding agencies in the public, commercial, or not-for-profit sectors.

\section{References}

[1] M. Ferreira, P. Seixas, P. Coutinho, Effect of nutritional status of semi-continuous microalgal cultures on the productivity and biochemical composition of Brachionus plicatilis, Mar. Biotechnol. (NY) 13 (2011) 1074-1085, https://doi.org/10.1007/ s10126-011-9370-y.

[2] P.M. Foley, E.S. Beach, J.B. Zimmerman, Algae as a source of renewable chemicals: opportunities and challenges, Green Chem. 13 (2011) 1399-1405, https://doi.org/ 10.1039/C1GC00015B.

[3] V.T. Duong, F. Ahmed, S.R. Thomas-Hall, S. Quigley, E. Nowak, P.M. Schenk, High protein- and high lipid-producing microalgae from northern Australia as potential feedstock for animal feed and biodiesel, Front. Bioeng. Biotechnol. 3 (2015) 53, https://doi.org/10.3389/fbioe.2015.00053.

[4] M.I. Khan, J.H. Shin, J.D. Kim, The promising future of microalgae: current status, challenges, and optimization of a sustainable and renewable industry for biofuel, feed and other products, Microb. Cell Factories 17 (2018) 36, https://doi.org/10. 1186/s12934-018-0879-x.

[5] A.S. Pedro, C.V. González-López, F.G. Acién, E. Molina-Grima, Outdoor pilot-scale production of Nannochloropsis gaditana: influence of culture parameters and lipid production rates in tubular photobioreactors, Bioresour. Technol. 169 (2014) 667-676, https://doi.org/10.1016/j.biortech.2014.07.052.

[6] R. Henderson, S.A. Parsons, B. Jefferson, The impact of algal properties and peroxidation on solid-liquid separation of algae, Water Res. 42 (2008) 1827-1845, https://doi.org/10.1016/j.watres.2007.11.039.

[7] J.C. Quinn, T. Yates, N. Douglas, K. Weyer, J. Butler, T.H. Bradley, P.J. Lammers, Nannochloropsis production metrics in a scalable outdoor photobioreactor for commercial applications, Bioresour. Technol. 117 (2012) 164-171, https://doi.org/ 10.1016/j.biortech.2012.04.073.

[8] A.S. Pedro, C.V. González-López, F.G. Acién, E. Molina-Grima, Outdoor pilot production of Nannochloropsis gaditana: influence of culture parameters and lipid production rates in raceway ponds, Algal Res. 8 (2015) 205-213, https://doi.org/ 10.1016/j. algal.2015.02.013.

[9] C. Martínez, O. Bernard, F. Mairet, Maximizing microalgae productivity by shading outdoor cultures, IFAC-PapersOnLine 50 (2017) 8734-8739, https://doi.org/10. 1016/j.ifacol.2017.08.1725.

[10] R. Davis, A. Aden, P.T. Pienkos, Techno-economic analysis of autotrophic microalgae for biofuel production, Appl. Energy 88 (2011) 3524-3531, https://doi.org/ 10.1016/j.apenergy.2011.04.018.

[11] A. Sukenik, Y. Carmeli, T. Berner, Regulation of fatty acid composition by irradiance level in the eustigmatophyte Nannochloropsis sp, J. Phycol. 25 (1989) 686-692, https://doi.org/10.1111/j.0022-3646.1989.00686.x.

[12] M.L. Teoh, S.M. Phang, W.L. Chu, Response of Antarctic, temperate and tropical microalgae to temperature stress, J. Appl. Phycol. 25 (2013) 285-297, https://doi. org/10.1007/s10811-012-9863-8.

[13] A. Juneja, R. Ceballos, G.S. Murthy, Effects of environmental factors and nutrient availability on the biochemical composition of algae for biofuels production: a review, Energies 6 (2013) 4607-4638, https://doi.org/10.3390/en6094607.

[14] A.K. Minhas, P. Hodgson, C.J. Barrow, A. Adholeya, A review on the assessment of 
stress conditions for simultaneous production of microalgal lipids and carotenoids, Front. Microbiol. 7 (2016) 546, https://doi.org/10.3389/fmicb.2016.00546.

[15] M. Olofsson, T. Lamela, E. Nilsson, J.P. Bergé, V. Pino, P. Uronen, C. Legrand, Seasonal variation of lipids and fatty acids of the microalgae Nannochloropsis oculata grown in outdoor large-scale photobioreactors, Energies 5 (2012) 1577-1592, https://doi.org/10.3390/en5051577.

[16] K.H. Park, C.G. Lee, Optimization of algal photobioreactors using flashing lights, Biotechnol. Bioprocess Eng. 5 (2000) 186-190, https://doi.org/10.1007/ BF02936592.

[17] A. Richmond, Z. Cheng-Wu, Optimization of flat pate glass reactor for mass production of Nannochloropsis sp. outdoors, J. Biotechnol. 85 (2001) 259-269, https:// doi.org/10.1016/S0168-1656(00)00353-9.

[18] L. He, V.R. Subramanian, Y.J. Tang, Experimental analysis and model-based optimization of microalgae growth in photo-bioreactors using flue gas, Biomass Bioenergy 41 (2012) 131-138, https://doi.org/10.1016/j.biombioe.2012.02.025.

[19] W.L. Chu, Strategies to enhance production of microalgal biomass and lipids for biofuel feedstock, Eur. J. Phycol. 52 (2017) 419-437, https://doi.org/10.1080/ 09670262.2017.1379100.

[20] L. de Winter, L.W. Schepers, M. Cuaresma, M.J. Barbosa, D.E. Martens, R.H. Wijffels, Circadian rhythms in the cell cycle and biomass composition of Neochloris oleoabundans under nitrogen limitation, J. Biotechnol. 187 (2014) 25-33, https://doi.org/10.1016/j.jbiotec.2014.07.016.

[21] M. Mittag, Circadian rhythms in microalgae, Int. Rev. Cytol. 206 (2001) 213-247, https://doi.org/10.1016/S0074-7696(01)06023-5.

[22] Q. Hu, N. Kurano, M. Kawachi, I. Iwasaki, S. Miyachi, Ultrahigh-cell-denstiy culture of a marine alga Chlorococcum littorale in a flat-plane photobioreactor, Appl. Microbiol. Biotechnol. 49 (1998) 655-662, https://doi.org/10.1007/ s002530051228.

[23] G. Torzillo, A. Sacchi, R. Materassi, A. Richmond, Effect of temperature on yield and night biomass loss in Spirulina platensis grown outdoors in tubular photobioreactors, J. Appl. Phycol. 3 (1991) 103-109, https://doi.org/10.1007/BF00003691.

[24] S.J. Edmundson, M.H. Huesemann, The dark side of algae cultivation: characterizing night biomass loss in three photosynthetic algae, Chlorella sorokiniana, Nannochloropsis salina and Picochlorum sp, Algal Res. 12 (2015) 470-476, https:// doi.org/10.1016/j.algal.2015.10.012.

[25] L. Oescheger, C. Posten, Construction and assessment parameters in photobioreactors, in: C. Posten, C. Walter (Eds.), Microalgal Biotechnology: Potential and Production, Walter de Gruyter GmbH, Berlin/Boston, 2012, pp. 225-236.

[26] A. Richmond, Large-scale microalgal culture and applications, in: F.E. Round, D.J. Chapman (Eds.), Progress in Physiological Research, 7 Biopress, Bristol, 1990, pp. 269-330 Vol. 7.

[27] F.G. Acién, J.M. Fernández, J.J. Magán, E. Molina, Production cost of a real microalgae production plant and strategies to reduce it, Biotechnol. Adv. 30 (2012) 1344-1353, https://doi.org/10.1016/j.biotechadv.2012.02.005.

[28] L. Rodolfi, Z.G. Chini, N. Bassi, G. Padovani, N. Biondi, G. Bonini, M.R. Tredici, Microalgae for oil: strain selection, induction of lipid synthesis and outdoor mass cultivation in a low-cost photobioreactor, Biotechnol. Bioeng. 102 (2009) 100-112, https://doi.org/10.1002/bit.22033.

[29] A. Sukeni, J. Beardall, J.C. Kromkamp, J. Kopecky, J. Masojídek, S. Bergeijk, S. Gabai, E. Shaham, A. Yamshon, Photosynthetic performance of outdoor Nannochloropsis mass cultures under a wide range of environmental conditions, Aquat. Microb. Ecol. 56 (2009) 297-308, https://doi.org/10.3354/ame01309.

[30] D. Pal, I. Khozin-Golberg, Z. Cohen, S. Boussiba, The effect of light, salinity, and nitrogen availability on lipid production by Nannochloropsis sp, Appl. Microbiol. Biotechnol. 90 (2011) 1429-1441, https://doi.org/10.1007/s00253-011-3170-1.

[31] D. Simionato, E. Sforza, C.E. Corteggiani, A. Bertucco, G.M. Giacometti, T. Morosinotto, Acclimation of Nannochloropsis gaditana to diferente illumination regimes: effects on lipid accumulation, Bioresour. Technol. 102 (2011) 6026-6032, https://doi.org/10.1016/j.biortech.2011.02.100.

[32] M. Olofsson, T. Lamela, E. Nilsson, J.P. Bergé, V. Pino, P. Uronen, C. Legrand, Combined effects of nitrogen concentration and seasonal changes on the production of lipids in Nannochloropsis oculate, Mar. Drugs 12 (2014) 1891-1910, https://doi. org $/ 10.3390 / \mathrm{md} 12041891$.

[33] J. Fabregas, J. Abalde, C. Herrero, B. Cabezas, M. Veiga, Growth of the marine microalga Tetraselmis suecica in batch cultures with different salinities, Aquaculture 42 (1984) 207-215, https://doi.org/10.1016/0044-8486(84)90101-7.

[34] L.S. Clesceri, A.E. Greenberg, R.R. Trussell, Standard Methods for the Examination of Water and Wastewater, American Public Health Association, American Waterworks Association, Water Pollution Control Federation, Washington D.C, 1989 (2134 pp).

[35] C.J. Zhu, Y.K. Lee, Determination of biomass dry weight of marine microalgae, J. Appl. Phycol. 9 (1997) 184-194, https://doi.org/10.1023/A:1007914806640.

[36] K.E. Dickinson, C.G. Whitney, P.J. McGinn, Nutrient remediation rates in municipal wastewater and their effect on biochemical composition of the microalga Scenedesmus sp. AMDD, Algal Res. 2 (2013) 127-134.

[37] E.G. Bligh, W.J. Dyer, A rapid method of total lipid extraction and purification, Can. J. Biochem. Physiol. 37 (1959) 911-917, https://doi.org/10.1139/059-099.

[38] N. Nogueira, N. Cordeiro, M.J. Aveiro, Chemical composition, fatty acids profile and cholesterol content of commercialized marine fishes captured in northeastern Atlantic, J. Fish. Sci. 7 (2013) 271-286, https://doi.org/10.3153/jfscom.2013029.

[39] A. Richmond, Handbook of Microalgal Mass Culture: Biotechnology and Applied Phycology, Blackwell Science Ltd, 2004.

[40] K. Loubiere, J. Pruvost, F. Aloui, J. Legrand, Investigations in an external-loop airlift photobioreactor with annular light chambers and swirling flow, Chem. Eng. Res. Des. 89 (2011) 164-171, https://doi.org/10.1016/j.cherd.2010.06.001.

[41] N. Biondi, N. Bassi, G.C. Zittelli, D. Faveri, A. Giovannini, L. Rodolfi, C. Allevi, C. Macrì, M. Tredici, Nannochloropsis sp. F\&M-M24: oil production, effect of mixing on productivity and growth in an industrial wastewater, Environ. Prog.
Sustain. Energy 32 (2013) 846-853, https://doi.org/10.1002/ep.11681.

[42] R.J. Camacho, C.A.M. González, G.M.C. Cerón, S.J.M. Fernández, F.F.G. Acién, G.E. Molina, A quantitative study of Eicosapentaenoic acid (EPA) production by Nannochloropsis gaditana for aquaculture as a function of dilution rate, temperature and average irradiance, Appl. Microbiol. Biotechnol. 98 (2014) 2429-2440, https://doi.org/10.1007/s00253-013-5413-9.

[43] Y. Ma, Z. Wang, C. Yu, Y. Yin, G. Zhou, Evaluation of the potential of 9 Nannochloropsis strains for biodiesel production, Bioresour. Technol. 167 (2014) 503-509, https://doi.org/10.1016/j.biortech.2014.06.047.

[44] J.C. Rodríguez, M.C. Cerón-García, J.M.F. Sevilla, E.M. Grima, The influence of culture conditions on biomass and high value product generation by Nannochloropsis gaditana in aquaculture, Algal Res. 11 (2015) 63-73, https://doi. org/10.1016/j.algal.2015.05.017.

[45] G.E. Fogg, O.C. Martinez, Effects of bottle size in determinations of primary productivity by phytoplankton, Hydrobiologia 173 (1989) 89-94, https://doi.org/10 1007/BF00015518.

[46] T. Granata, Dependency of microalgal production on biomass and the relationship to yield and bioreactor scale-up for biofuels: a statistical analysis of $60+$ years of algal bioreactor data, Bioenergy Res 10 (2017) 267-287, https://doi.org/10.1007/ s12155-016-9787-2.

[47] E.M. Grima, J.A.S. Pérez, F.G. Camacho, J.L.G. Sánchez, Outdoor culture of Isochrysis galbana ALII-4 in a closed tubular photobioreactor, J. Biotechnol. 37 (1994) 159-166, https://doi.org/10.1016/0168-1656(94)90007-8.

[48] J. Fábregas, A. Maseda, Changes in the cell composition of the marine microalga, Nannochloropsis gaditana, during a light:dark cycle, Biotecnhol. Lett. 24 (2002) 1699-1703, https://doi.org/10.1023/A:1020661719272.

[49] A.F. Talebi, S.K. Mohtashami, M. Tabatabaei, M. Tohidfar, A. Bagheri, M. Zeinalabedini, H.H. Mirzaei, M. Mirzajanzadeh, S.M. Shafaroudi, S. Bakhtiari, Fatty acids profiling: a selective criterion for screening microalga strain for biodiesel production, Algal Res. 2 (2013) 258-267, https://doi.org/10.1023/ A:1020661719272.

[50] Q. Hu, W. Xiang, S. Dai, T. Li, F. Yang, Q. Jia, G. Wang, H. Wu, The influence of cultivation period on growth and biodiesel properties of microalga Nannochloropsis gaditana 1049, Bioresour. Technol. 192 (2015) 157-164, https://doi.org/10.1016/ j.biortech.2015.04.106.

[51] B. Tamburic, S. Guruprasad, D.T. Radford, M. Szabó, R.M. Lilley, A.W.D. Larkum, J.B. Franklin, D.M. Kramer, S.I. Blackburn, J.A. Raven, M. Schliep, P.J. Ralph, The effect of diel temperature and light cycles on the growth of Nannochloropsis oculate in a photobioreactor matrix, PloS One 9 (2014) e86047, , https://doi.org/10.1371/ journal.pone.0086047.

[52] E. Sforza, D. Simionato, G.M. Giacometti, A. Betucco, T. Morosinotto, Adjusted light and dark cycles can optimize photosynthetic efficiency in algae growing in photobioreactors, PloSOne 7 (2012) e38975, https://doi.org/10.1371/journal.pone. 0038975.

[53] G. Benvenuti, R. Bosma, F. Ji, P.P. Lamers, M.J. Barbosa, R.H. Wijffels, Batch and semi-continuous microalgal TAG production in lab-scale and outdoor photobioreactors, J. Appl. Phycol. 28 (2016) 3167-3177, https://doi.org/10.1007/ s10811-016-0897-1.

[54] X.N. Ma, T.P. Chen, B. Yang, J. Liu, F. Chen, Lipid production in Nannochloropsis, Mar. Drugs. 14 (2016) 61-78, https://doi.org/10.3390/biology8010005.

[55] E.R. Marco, M.E. Steffolani, M.L. Martínez, A.E. León, The use of Nannochloropsis sp. as a source of omega-3 fatty acids in dry pasta: chemical, technological and sensory evaluation, Int. J. Food Sci. Tech. 53 (2018) 499-507, https://doi.org/10.1111/ijfs. 13609.

[56] T.M. Mata, A.A. Martins, N.S. Caetano, Microalgae for biodiesel production and other applications: a review, Renew. Sust. Energ. Rev. 14 (2010) 217-232, https:// doi.org/10.1016/j.rser.2009.07.020.

[57] G.C. Zittelli, F. Lavista, A. Bastianini, L. Rodolfi, M. Vincenzini, M.R. Tredici, Production of eicosapentaenoic acid by Nannochloropsis sp. cultures in outdoor tubular photobioreactors, J. Biotechnol. 70 (1999) 299-312, https://doi.org/10. 1016/S0168-1656(99)00082-6.

[58] J. Fabregas, A. Maseda, A. Domínguez, A. Otero, The cell composition of Nannochloropsis sp changes under different irradiances in semi-continuous culture, World J. Microbiol. Biotechnol. 20 (2004) 31-35, https://doi.org/10.1023/B:WIBI. 0000013288.67536.ed.

[59] J.C. Schneider, A. Livne, A. Sukenik, P.G. Roessler, A mutant of Nannochloropsis deficient in eicosapentaenoic acid production, Phytochemistry 40 (1995) 807-814, https://doi.org/10.1016/0031-9422(95)00365-E.

[60] A. Sukenik, Y. Carmeli, Lipid synthesis and fatty acid composition in Nannochloropsis sp. (Eustigmatophyceae) grown in a light dark-cycle, J. Phycol. 26 (1990) 463-469, https://doi.org/10.1111/j.0022-3646.1990.00463.x.

[61] S. Renaud, D. Parry, L. Thinh, C. Kuo, A. Padovan, N. Sammy, Effect of light intensity on the proximate biochemical and fatty acid composition of Isochrysis sp., and Nannochloropsis oculata for use in tropical aquaculture, J. Appl. Phycol. 3 (1991) 43-53, https://doi.org/10.1007/BF00003918.

[62] M.A. Cobelas, J.Z. Lechado, Lipids in microalgae. A review. I. Biochemistry, Grasas Aceites 40 (1989) 118-145, https://doi.org/10.1016/j.rser.2019.04.052.

[63] D.A. Martins, L. Custódio, L. Barreira, H. Pereira, R. Ben-Hamadou, J. Varela, K.M. Abu-Salah, Alternative sources of $\mathrm{n}-3$ long-chain polyunsaturated fatty acids in marine microalgae, Mar. Drugs 11 (2013) 2259-2281, https://doi.org/10.3390/ md11072259.

[64] P. Singh, S. Kumari, A. Guldhe, R. Misra, I. Rawat, F. Bux, Trends and novel strategies for enhancing lipid accumulation and quality in microalgae, Renew. Sust. Energ. Rev. 55 (2016) 1-16, https://doi.org/10.1016/j.rser.2015.11.001.

[65] K.J.M. Mulders, P.P. Lamers, R.H. Wijffels, D.E. Martens, Dynamics of biomass composition and growth during recovery of nitrogen-starved Chromochloris zofingiensis, Appl. Microbiol. Biotechnol. 99 (2014) 1873-1884, https://doi.org/10. 1007/s00253-014-6181-x. 